Neth. J. Pl. Path. 99 (1993) 205-217

\title{
Effects of leaf blast on photosynthesis of rice. 2. Canopy photosynthesis
}

\author{
L. BASTIAANS 1.2 and M.J. KROPFF 2 \\ 1 Department of Theorctical Production Ecology, Wageningen Agricultural University, P.O. Box \\ 430, $6700 \mathrm{AK}$ Wageningen, the Netherlands \\ ${ }^{2}$ International Rice Research Institute, P.O. Box 933, 1099 Manila, the Philippines
}

Accepted 15 January 1993

\begin{abstract}
The effect of Pyricularia oryzae, the causal organism of leaf blast in rice, on photosynthetic rate of a rice crop was determined with mobile equipment in the field. Canopy $\mathrm{CO}_{2}$ exchange rate (CER) was significantly reduced in plots inoculated with $P$. oryzae. The experimentally obtained data were used to evaluate the performance of a model for the effects of leaf blast on canopy photosynthesis. The model comprised photosynthesis and respiration routines of a mechanistic crop growth model, extended with submodels for effects of leaf blast on both processes. Canopy photosynthesis and the effect of leaf blast on CER were accurately simulated with the model.

Analysis showed that the reduction in canopy photosynthesis was mainly due to an adverse effect of lesions on leaf photosynthetic rate and to shading by dead leaf area resulting from disease induced senescence. A sensitivity analysis demonstrated the importance of the vertical distribution of the disease in the canopy. This implies that disease monitoring for crop loss assessment should consider vertical disease distribution.
\end{abstract}

Additional keyu'ords: Pyricularia oryzae, Oryza sativa, simulation model, respiration, vertical distribution.

\section{Introduction}

Leaf blast (causal organism: Pyricularia oryzae Cavara) is an important constraint for the production of rice (Oryza sativa L.). Infection by the fungus in the vegetative growth phase of rice leads to formation of typical spindle-shape lesions on leaves. Heavily infected leaves die completely. Goto (1965) tried to mimic leaf blast injury in experiments by progressive artificial defoliation of a disease-free canopy. However, grain yield of the artificially defoliated plants was greater than that of diseased rice plants, indicating that leaf blast influenced the host plant more than just through a loss in leaf area. This conclusion is supported by Toyoda and Suzuki (1957), who observed an increased respiration in the surrounding green tissue of blast lesions. Moreover, Bastiaans (1991) measured that leaf blast reduced photosynthetic rate of the remaining green part of infected leaves.

The importance of the observed effects of leaf blast on leaf physiology, as determined by their effect on grain yield, is difficult to assess. Effects on leaf physiology and effects on grain yield represent two different levels of aggregation, and are therefore difficult to relate. Mechanistic crop growth models can help to bridge the gap between these two aggregation levels. This approach starts with the quantification of the effect of the disease on basic plant growth processes. Submodels simulating these effects are then coupled to models simulating growth and production of the crop, in order to estimate the effect on 
yield (Rabbinge and Rijsdijk, 1981; Boote et al., 1983; Rabbinge and Bastiaans, 1989). Kropff (1989), in a study on the effects of $\mathrm{SO}_{2}$ on production of a broad bean crop (Vicia faba L.), refined the described approach. In between the quantification of effects of $\mathrm{SO}_{2}$ on leaf physiology and the use of the crop growth model for the estimation of effects on yield, he introduced a validation of the model at an intermediate aggregation level. Canopy photosynthesis was measured in the field and used to evaluate the performance of a model for the effects of $\mathrm{SO}_{2}$ on canopy photosynthesis. The thus validated model was later on introduced in a crop growth model to analyse and predict effects on crop yield.

In the present study the effect of leaf blast on canopy photosynthesis was explained from the effect leaf blast has on photosynthesis characteristics of individual leaves. Relations between leaf blast severity and the assimilation rate at light saturation $\left(P_{\text {max }}\right)$, the initial light use efficiency $(\epsilon)$ and the rate of dark respiration $\left(R_{d}\right)$ of rice leaves were determined in a previous study (Bastiaans, 1993). These relations were used to construct a model for effects of leaf blast on canopy photosynthesis. Photosynthetic rate of rice canopies infected with $P$. oryzae was determined in a field experiment, to evaluate the performance of the model. In addition, the model was used to quantify the contribution of the various damage mechanisms to the reduction in canopy photosynthesis. Moreover, the importance of the vertical disease distribution was determined.

\section{Materials and methods}

Plant material and inoculation. In the 1990 wet season, a field experiment was conducted at the lowland research site of the International Rice Research Institute (IRRI), Los Baños, Philippines. On 6 November, 13-day-old rice seedlings of cultivar IR50 were transplanted in a plot of $750 \mathrm{~m}^{2}$. Plants were grown under irrigated conditions. Fertilizer was applied one day before transplanting (N-P-K: $\left.60-50-50 \mathrm{~kg} \mathrm{ha}^{-1}\right)$. Additional nitrogen was applied at a rate of $30 \mathrm{~kg} \mathrm{~N} \mathrm{ha-1}$ at 29 days after transplanting (DAT). Insecticides (triazophos at 8 and 27 DAT, carbofuran at $17 \mathrm{DAT}$ ) were applied to control insects. Three plots of $12 \mathrm{~m} \times 3.6 \mathrm{~m}$ were pegged out, of which one (plot A), was used as control. The other two plots were inoculated with P. oryzae (isolate PO6-6). Plot B was inoculated at 27 and 34 DAT, whereas plot $C$ was inoculated at 20 and 34 DAT. Timing of the first inoculation varied, to establish two different levels of leaf blast. Inoculum was prepared as described by Mackill and Bonman (1986) and the spore density was adjusted to 75000 conidia $\mathrm{ml}^{-1}$. Gelatine was added to the inoculum in a concentration of $2.5 \mathrm{gL}^{-1}$. Per inoculation $5 \mathrm{~L}$ of inoculum was sprayed per plot. The night after inoculation, plots were covered with plastic to increase leaf wetness duration. Covering was repeated during the following 3 nights, after spraying of $5 \mathrm{~L}$ distilled water per plot.

Canopy photosynthesis measurements. Canopy $\mathrm{CO}_{2}$ exchange rate $\left(\mathrm{CER} ; \mu \mathrm{g} \mathrm{CO}_{2} \mathrm{~m}^{-2} \mathrm{~s}^{-1}\right)$ was measured on 19 December (43 DAT) between 1115 and $1215 \mathrm{~h}$ using a mobile gas exchange system (Walz, Effeltrich, Germany) according to the procedure described by Dingkuhn et al. (1990). A transparant mylar-covered chamber with an aluminum frame $(0.4 \times 0.4 \times 0.75 \mathrm{~m})$ was placed over the canopy $(2 \times 2$ hills $)$ for less than $90 \mathrm{~s}$ while a continuously flowing air sample was collected through a $20 \mathrm{~m}$ teflon tubing. The $\mathrm{CO}_{2}$ concentration of the gas sample was determined with a BINOS- 1 infrared gas analyzer (Heraeus, Hanau, Germany). Gas mixing and wind generation inside the chamber were achieved using a fan located just above the canopy. The $\mathrm{CO}_{2}$ exchange rate of the canopy was calculated from the rate of linear decrease in sample $\mathrm{CO}_{2}$ concentration. Net canopy photosynthesis was computed by subtracting the separately determined floodwater $\mathrm{CO}_{2}$ release $\left(175 \mu \mathrm{g} \mathrm{CO}_{2} \mathrm{~m}^{-2} \mathrm{~s}^{-1}\right)$ from canopy $\mathrm{CO}_{2}$ exchange. Average conditions at the time of 
measurement were: $360 \mathrm{Jm}^{-2} \mathrm{~s}^{-1}$ of photosynthetically active radiation (PAR; $400-700 \mathrm{~nm}$ ) and a temperature of 30 " $\mathrm{C}$. Absorption of light by the mylar-covered chamber was about $10 \%$.

Measurements were followed by destructive plant sampling for a layerwise determination of canopy characteristics and disease intensity. Leaves were classified according to the distance from stem base to leal collar $(<0.10 \mathrm{~m}, 0.10$ to $0.15 \mathrm{~m}, 0.15$ to $0.20 \mathrm{~m}$, and $>0.20 \mathrm{~m}$ ). Within each height category, leaves of healthy (with no lesions), diseased (with at least one blast lesion) and dead type were distinguished. Leaf area was determined for each type separately. Disease severity, defined as the fraction of green leaf area covered by lesions, was estimated by scoring the number and size of lesions on a randomly selected leaf sample. Dry weight of green (healthy and diseased) leaf biades, of dead leaf blades, and of stems + leaf sheaths was determined, as was $\mathrm{N}$ concentration of green leaf tissue (Kjeldahl).

Based on the distribution of leaf area over height categories and the average leaf blade length, a reconstruction of the canopy was made, assuming an average leaf angle of 65 degrees. The reconstructed canopy was divided in five layers of equal height. Leaf characteristics (specific leaf weight and $\mathrm{N}$-content), disease severity and the fraction dead leaf area were calculated per layer. These data, and the dry weight of the various shoot organs, were used as model inputs.

Modelling instantaneous canopy photosynthesis (CER). In order to compare simulated effects of leaf blast with measurements, a model for calculation of the diurnal course of instantaneous canopy photosynthesis was developed. The model comprised routines for calculation of photosynthesis and respiration of an elementary model for crop growth (Penning de Vries et al., 1989), and routines to generate diumal trends of radiation and temperature on the basis of daily weather data. The model was run with a time interval of $0.25 \mathrm{~h}$.

The procedure for calculation of gross canopy photosynthesis was basically identical to the procedure described by Spitters (1986). Daily global irradiance was input to the model, and used to generate diurnal trends of total, direct and diffuse radiation reaching the top of the canopy (Spitters et al., 1986). After accounting for reflection, the light profile within the canopy was determined by calculating the decrease in radiation flux with canopy depth for both diffuse and direct radiation (Goudriaan, 1988). On the basis of both light profiles, absorption can be derived for any depth within the canopy. Substitution into the photosynthesis-light response of single leaves then gives the assimilation rate per unit leaf area at the concerning depth in the canopy. In this model, five canopy layers were distinguished and the instantaneous photosynthesis per canopy layer was calculated using a three-point Gaussian integration (Goudriaan, 1986). Instantaneous canopy photosynthesis was obtained by adding up the photosynthesis of the five layers. A negative exponential function, comprising the gross assimilation rate at light saturation $\left(P_{g \text { max }}\right)$ and the initial light use efficiency $(\epsilon)$, was used to describe the $\mathrm{CO}$, assimilation-light response of individual leaves (Goudriaan, 1982). $P_{\text {g.max }}$ was related to leaf $\mathrm{N}$-content $\left(\mathrm{g} \mathrm{N} \mathrm{m}^{-2}\right)$, according to the relationship derived by Penning de Vries et al. (1990).

Respiration was modelled according to the principles of McCree (1970) and Thornley (1970), who assumed that the produced assimilates were used for either maintenance or growth. In the model maintenance was assumed to take precedence over growth. Maintenance respiration was calculated per organ and proportional to the organ dry weight. To account for an effect of temperature $\left(Q_{10}=2\right.$; Penning de Vries, 1975), daily minimum and maximum temperature were inputs to the model. The diurnal trend of temperature was generated according to Parton \& Logan (1981). To express the depend- 
ence of maintenance respiration on metabolic activity (Penning de Vries, 1975), maintenance was further related to gross photosynthesis. This part of maintenance respiration was estimated to be equal to ten percent of gross canopy photosynthesis (Penning de Vries et al., 1989).

The assimilates remaining after provision of maintenance respiration, were used as substrate for growth. Substrate utilization for growth was assumed to proceed according to a first order rate of decay, and the half-life of this process was related to temperature according to observations of McCree (1974; for white clover and sorghum) and Ryle et al. (1976; for barley). Growth respiration reflects the metabolic costs of converting assimilates into structural dry matter. Growth respiration and growth were calculated per organ and based on the production values of biochemical components calculated by Penning de Vries (1972).

CER was calculated as gross photosynthesis minus maintenance and growth respiration. Comparison of model results with measurements of Dingkuhn et al. (1990), who measured CER at various times during the day, demonstrates that the model gives a realistic simulation of the diumal course of canopy photosynthesis (Fig. 1). Instantaneous crop growth rate was obtained through summation of organ growth rates. This rate was integrated over the day to obtain the daily crop growth rate (CGR; g dry matter $\mathrm{m}^{-2} \mathrm{~d}^{-1}$ ).

Modelling the effects of leaf blast. To account for the effect of leaf blast on photosynthesis, disease severity and the fraction dead leaf area were specified per layer. Photosynthesis-light response characteristics of green leaf tissue (healthy + diseased leaves) were related to observed disease severity, using parameter $\beta$ (Bastiaans, 1993). This

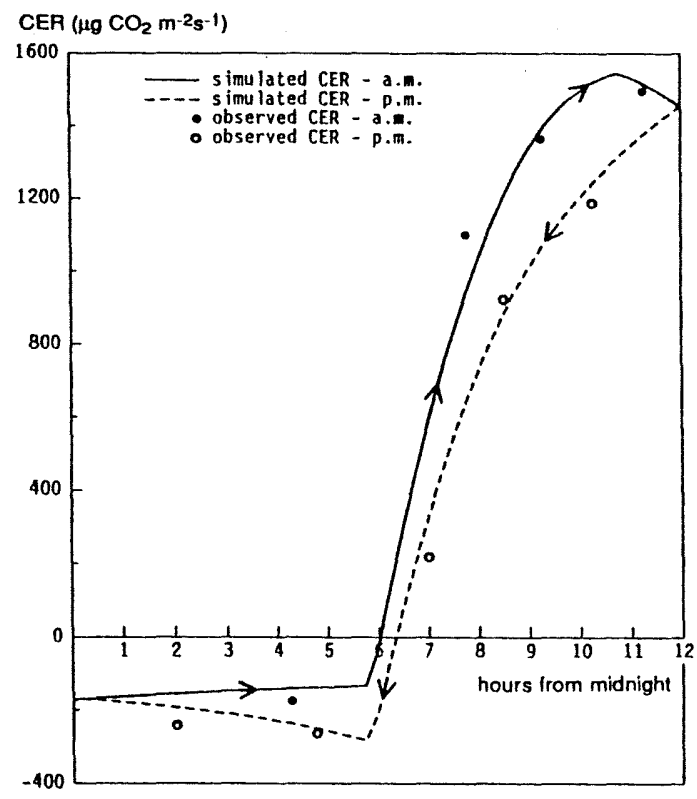

Fig. 1. Simulated and measured diurnal course of canopy $\mathrm{CO}$, exchange rate $\left(\mathrm{CER} ; \mu \mathrm{g} \mathrm{CO} \mathrm{m}^{-2} \mathrm{~s}^{-1}\right)$ of a direct seeded rice crop of IR64 at 69 days after seeding. Model inputs and measured CER are derived from Dingkuhn et al. (1990). 
proportionality constant expresses the ratio between the reduction in photosynthetic rate due to the presence of a single lesion and the expected reduction according to visible lesion size. The reduction in $P$ and $\epsilon$ were characterized by $\beta$-values of 3.7 and 3.0 , respectively (Bastiaans, 1991 \& 1993). Typical photosynthesis-light response curves of diseased leaf tissue are given in Fig. 2. Dead leaves did not contribute to photosynthesis, but light interception by this part of the canopy was accounted for. Optical characteristics of diseased and dead leaf tissue were assumed to be identical to the characteristics of healthy leaf tissue.

The effect of leaf blast on respiration was introduced as an increased rate of leaf maintenance respiration. Implicitely, this assumes that assimilate requirement of processes related to the presence of the disease have priority over growth. The increase in respiration was related to disease severity and characterized by parameter $\rho$ (Bastiaans, 1993). This parameter expresses the ratio between the respiration related to the presence of a single lesion and the respiration of an identical area of green leaf tissue. Following Bastiaans (1993), a value of 4.5 was used. Maintenance requirement of dead leaf tissue is nil and was therefore not considered.

Model validation and application. CER observed in the present experiment was compared with the simulated CER at the time of actual measurement, to validate model performance. After validation, the model was used to analyse the importance of the various damage mechanisms. For this analysis the effect on CGR was studied, since this value contains the influence of the disease integrated over the day. In addition, a sensitivity analysis was carried out for parameters characterizing the effect of leaf blast on photosynthesis and respiration $\left(\beta p_{\max }, \beta_{\epsilon}, \rho\right)$. Finally, the model was used to examine the importance of the vertical disease distribution.

Gross photosynthesis $\left(\mu \mathrm{g} \mathrm{CO} 2 \mathrm{~m}^{-2} \mathrm{~s}^{-1}\right)$

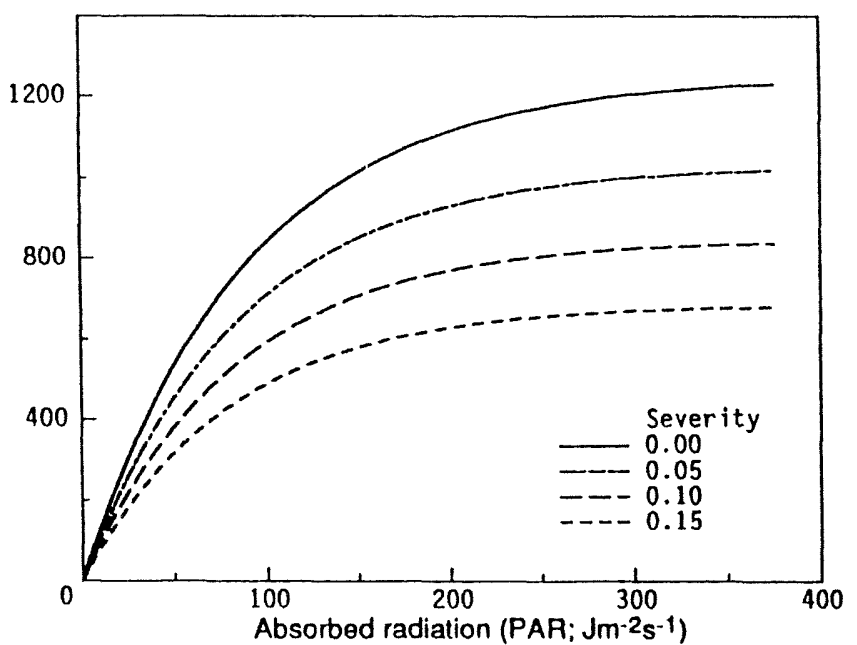

Fig. 2. Photosynthesis-light response curves of standardized rice leaves (leaf $\mathrm{N}$-content $1.5 \mathrm{~g} \mathrm{~N} \mathrm{~m}^{-2}$; specific leaf weight $30 \mathrm{gm}^{-2}$ ), demonstrating the effect of leaf blast on gross photosynthetic rate. Curves summarize the results of earlier observations (Bastiaans, 1991 \& 1993).

Neth.J.Pl.Path. 99 (1993) 


\section{Results}

Measured effect of leaf hlast on CER. Table 1 gives relevant characteristics of the canopies in the various plots at the time of photosynthesis measurement. The control plot was slightly infected, due to influx of spores from neighbouring plots. A small amount of dead leaf area, found in the lower part of the canopy, consisted of naturally senescing leaves. In plot B and C disease severity and the fraction dead leaf area were higher than in plot A. The fraction dead leaf area was moderate in plot B and high in plot C. In Fig. 3

Table 1. Characteristics of rice canopies at the time of photosynthesis measurement and measured canopy $\mathrm{CO}_{2}$ exchange rate (CER).

\begin{tabular}{lcccccccc}
\hline Characteristic & Plot A & \multicolumn{3}{c}{ Plot B } & \multicolumn{1}{c}{ Plot C } & \multicolumn{2}{c}{ S.E.D. ${ }^{1}$} \\
Number of observations & 6 & & 4 & & 4 & & & \\
Plant height $(\mathrm{m})$ & 0.68 & $(\mathrm{a})^{2}$ & 0.60 & (b) & 0.54 & (c) & 0.02 & $(0.02)$ \\
Shoot dry weight $\left(\mathrm{gm}^{-2}\right)$ & 291. & (a) & 274. & (a) & 298. & (a) & 20. & $(22)$. \\
Leaf area index & 4.49 & (a) & 4.80 & (a) & 4.66 & (a) & 0.39 & $(0.43)$ \\
Leaf N-content $\left(\mathrm{g} \mathrm{N} \mathrm{m}^{-2}\right)$ & 1.21 & (a) & 1.14 & (a) & 1.18 & (a) & 0.04 & $(0.04)$ \\
Specific leaf weight $\left(\mathrm{gm}^{-2}\right)$ & 34.3 & (a) & 30.7 & (b) & 31.2 & (b) & 0.9 & $(1.0)$ \\
Disease severity & 0.003 & (a) & 0.046 & (b) & 0.044 & (b) & 0.9 & $(1.0)^{4}$ \\
Fraction dead leaf area & 0.01 & (a) & 0.03 & (b) & 0.15 & (c) & 1.5 & $(1.6)^{4}$ \\
CER $\left(\mu \mathrm{g} \mathrm{CO}_{2} \mathrm{~m}^{-2} \mathrm{~s}^{-1}\right)$ & 1432. & (a) & 1219. & (b) & 953. & (c) & 57. & $(62)$. \\
\hline
\end{tabular}

' Standard error of difference of means applied to comparison of plot A with plot B or C. and plot $B$ with plot $C$ (values in parentheses).

${ }^{2}$ Means in the same row followed by the same letter are not significantly different according to $t$-test $(P<0.05)$.

${ }^{3}$ Fraction of green (healthy + diseased) leaf area covered by lesions.

${ }^{4}$ Data were analysed after arc sine transformation. S.E.D.-values of transformed data are given.
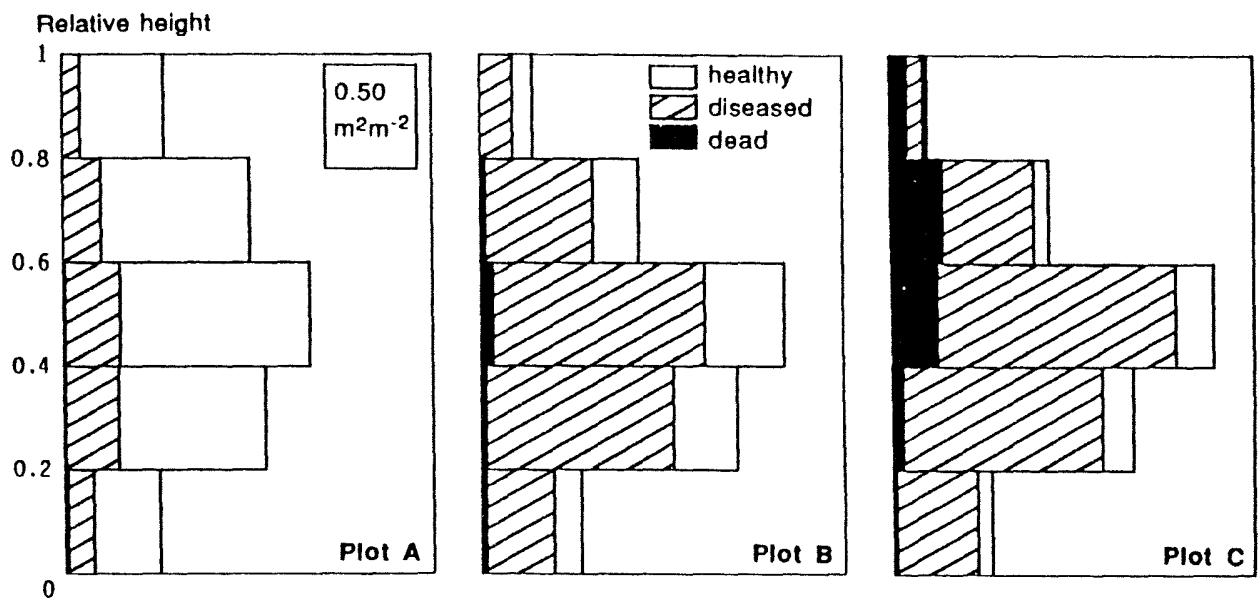

Fig 3. Vertical distribution of healthy, diseased and dead leaf area of the rice crop in the 3 experimental plots. Height is expressed on a relative scale. The rectangle in A represents 0.5 unit of leaf area. 
more details are given on the vertical distribution of healthy, diseased and dead leaf tissue. Plant height was clearly affected by the disease. Leaf area index was not affected, but leaves in the noninoculated plot had a higher specific leaf weight. Leaf nitrogen contents of the three plots were identical. In all plots a $\mathrm{N}$-profile was found, with leaf $\mathrm{N}$-content in the top layer about $30 \%$ higher than in the bottom layer. Significant differences between CER of the three plots were observed. Compared to the control plot the CER's in plot B and $\mathrm{C}$ were reduced by $15 \%$ and $33 \%$, respectively.

Analysis of damage mechanisms. Canopy $\mathrm{CO}_{2}$ exchange rate for control and inoculated canopies was accurately simulated with the model (Fig. 4). The observed reduction in CER can thus be explained by the adverse effect of blast lesions on leaf photosynthetic rate and respiration and by the existence of dead leaf tissue, resulting from disease induced senescence. In Table 2 a detailed analysis of the reduction in CGR is given. The effects of blast lesions and dead leaf tissue were separated, and further dissected. Lesions cause a decrease in green leaf tissue, a reduction in photosynthetic rate of the remaining green leaf tissue, and an increased respiration. In successive runs these damage mechanisms were removed one after the other, and the subsequent increase in CGR was defined as the reduction due to the newly removed damage mechanism. Clearly, the reduction in photosynthetic rate of the remaining green leaf tissue was the most important effect of blast lesions, whereas the increased respiration contributed only marginally to the overall effect.

Dead leaf tissue causes a reduction in photosynthetically active leaf tissue and reduces light intensity in lower leaf layers by light interception (shading). The increase in simulated CGR after removal of dead leaf tissue corresponds to the reduction due to shading. The further increase in simulated CGR after replacing dead leaf tissue by an identical area of healthy leaf tissue, equals the reduction due to the reduction in photosynthetically active leaf tissue. The analysis showed that, in canopies where dead leaf tissue was present in the upper part, shading accounted for two thirds of the overall reduction due to dead leaf tissue (plot B and C). Shading was relatively less important when dead leaf tissue was present in the lower part of the canopy (plot A).

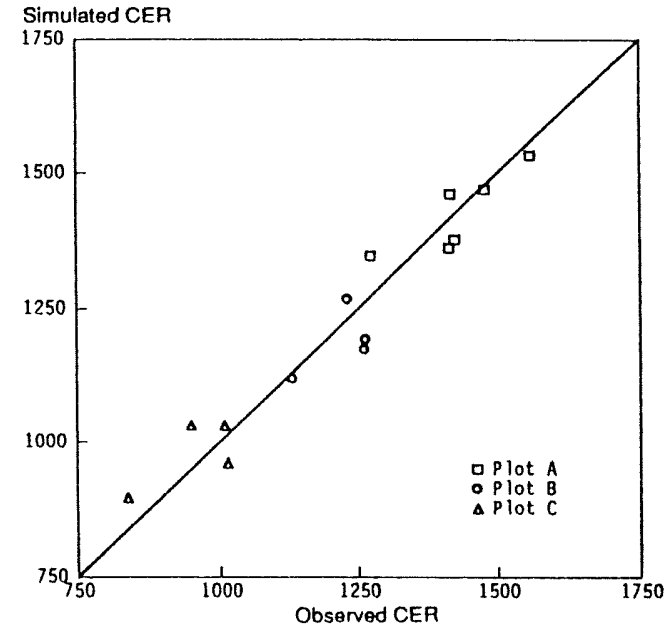

Fig. 4. Comparison of observed and simulated canopy $\mathrm{CO}_{2}$ exchange rate ( $\left.\mathrm{CER} ; \mathrm{mg} \mathrm{CO}_{2} \mathrm{~m}^{-2} \mathrm{~s}^{-1}\right)$.

Neth. J. Pl. Path. 99 (1993) 
Table 2. Contribution of blast lesions and dead leaf tissue to the overall reduction in growth rate of rice crops with different levels of leaf blast (Table 1), as simulated with the model. The contribution of the identified damage mechanisms related to blast lesions and dead leaf tissue are specified and expressed as a percentage of the total reduction due to blast lesions and dead leaf tissue, respectively. CGR is crop growth rate in $\mathrm{g}$ dry matter $\mathrm{m}^{2} \mathrm{~d}^{-1}$.

\begin{tabular}{|c|c|c|c|c|c|c|}
\hline Characteristic & Plot A & & Plot B & & Plot C & \\
\hline CGR of a healthy canopy' & 21.3 & & 21.2 & & 21.5 & \\
\hline Total reduction in CGR due to leaf blast & 0.3 & $(1.00)$ & 4.0 & $(1.00)$ & 8.0 & $(1.00)$ \\
\hline Reduction in CGR due to blast lesions & 0.2 & $(0.66)$ & 3.2 & $(0.81)$ & 2.7 & $(0.34)$ \\
\hline $\begin{array}{l}\text { - decrease in green leaf tissue } \\
\text { - reduction in leaf photosynthetic rate } \\
\text { - increase in respiration }\end{array}$ & & $\begin{array}{r}29 \% \\
65 \% \\
6 \%\end{array}$ & & $\begin{array}{r}31 \% \\
63 \% \\
6 \%\end{array}$ & & $\begin{array}{r}30 \% \\
64 \% \\
6 \%\end{array}$ \\
\hline $\begin{array}{l}\text { Reduction in CGR due to dead leaf tissue } \\
\text { Contribution of identified damage mechanisms: }\end{array}$ & 0.1 & $(0.34)$ & 0.8 & $(0.19)$ & 5.3 & $(0.66)$ \\
\hline $\begin{array}{l}\text { - decrease in green leaf tissue } \\
\text { - shading }\end{array}$ & & $\begin{array}{l}52 \% \\
48 \%\end{array}$ & & $\begin{array}{l}32 \% \\
68 \%\end{array}$ & & $\begin{array}{l}30 \% \\
70 \%\end{array}$ \\
\hline
\end{tabular}

1 A healthy canopy is defined as a canopy in which disease severity is nil and dead leaf tissue is replaced by an identical area of healthy leaf tissue.

Summarizing the effects of the disease on CGR in an effect on radiation interception by green leaf area (RI) and an effect on radiation use efficiency (RUE), as proposed by Johnson (1987), demonstrated that leaf blast reduced both (Table 3). The reduction in RUE in plots $B$ and $C$ was almost identical. This reduction is mainly a result of the inhibitory effects of lesions on photosynthesis of the surrounding green leaf tissue, and therefore related to disease severity. Disease severity of both plots was nearly the same (Table 1). The difference in CGR of plot B and C was therefore mainly due to the difference in RI, and reflected the difference in fraction dead leaf area that existed due to a difference in onset of the epidemic.

Sensitivity analysis. A sensitivity analysis was carried out with a canopy identical to the average canopy observed in plot $B$. The analysis was focused on model parameters which characterize the effect of leaf blast on photosynthesis and respiration $\left(\beta p_{\text {mar }}, \beta_{\epsilon}\right.$ and $\rho$ ). The standard values of these parameters were reduced and increased with their standard error, and the model was run after every parameter change. The resulting reduction or increase in the simulated reduction in CGR was determined and expressed as a percentage of the simulated reduction in CGR due to blast lesions (Table 4). In addition, the relative

Table 3. Simulated crop growth rate (CGR) analysed in terms of radiation interception by green leaf area (RI) and radiation use efficiency (RUE), of canopies with a different level of leaf blast (Table 1).

\begin{tabular}{lcccccc}
\hline Characteristic & Plot A & \multicolumn{3}{c}{ Plot B } & \multicolumn{3}{c}{ Plot C } \\
& & & & & & \\
Simulated CGR (g dry matter $\left.\mathrm{m}^{-2} \mathrm{~d}^{-1}\right)$ & 21.0 & $(1.00)$ & 17.2 & $(0.82)$ & 13.5 & $(0.64)$ \\
- RI (MJm-2 $\mathrm{d}^{-1}$ ) & 8.1 & $(1.00)$ & 7.6 & $(0.94)$ & 5.9 & $(0.73)$ \\
- RUE $\left(\mathrm{g}\right.$ dry matter $\left.\mathrm{MJ}^{-1}\right)$ & 2.59 & $(1.00)$ & 2.27 & $(0.88)$ & 2.30 & $(0.89)$ \\
\hline
\end{tabular}


Table 4. Sensitivity of the simulated reduction in crop growth rate of rice to changes in model parameters that characterize the effect of leaf blast on $\mathrm{CO}_{2}$ assimilation rate at light saturation $\left(\beta p_{\text {max }}\right)$, initial light use efficiency $\left(\beta_{\epsilon}\right)$ and dark respiration $(\rho)$. The simulated percentage change in the reduction in crop growth rate due to a change in input value equal to the standard error $(\sigma)$ of the respective parameter is given. Relative sensitivity (RS) was calculated as the ratio of percentage change in the reduction in crop growth rate and percentage change in input parameter. The analysis was performed for a clear and a cloudy day, using the rice crop in plot B. Only the reduction in crop growth rate due to blast lesions was considered.

\begin{tabular}{|c|c|c|c|c|c|c|c|c|}
\hline \multirow[t]{3}{*}{ Parameter } & \multirow{3}{*}{$\begin{array}{l}\text { Standard } \\
\text { values' }\end{array}$} & \multirow[t]{3}{*}{$\sigma$} & \multicolumn{3}{|c|}{ Clear day } & \multicolumn{3}{|c|}{ Cloudy day } \\
\hline & & & \multicolumn{3}{|c|}{ Reduction } & \multicolumn{3}{|c|}{ Reduction } \\
\hline & & & $-\sigma$ & $+\sigma$ & RS & $-\sigma$ & $+\sigma$ & RS \\
\hline$\beta p_{\max }$ & 3.7 & 0.6 & $-6 \%$ & $+6 \%$ & +0.39 & $-2 \%$ & $+2 \%$ & +0.15 \\
\hline$\beta_{\epsilon}$ & 3.0 & 0.7 & $-10 \%$ & $+10 \%$ & +0.44 & $-15 \%$ & $+15 \%$ & +0.64 \\
\hline$\rho$ & 4.5 & 1.3 & $-2 \%$ & $+2 \%$ & +0.08 & $-4 \%$ & $+4 \%$ & +0.12 \\
\hline
\end{tabular}

' Parameter values and their standard error were derived from Bastiaans, 1991 \& 1993.

sensitivity of the parameters with respect to the reduction in CGR was calculated. Relative sensitivity was defined as the ratio of percentage change in simulated reduction and percentage change in parameter input value. Typical weather data for a clear and a cloudy day were obtained from IRRI's meteorological station, and used to compare sensitivity under various weather conditions.

Calculation of the ratio between the standard error and the mean of the various parameters gave values of $0.16,0.23$ and 0.29 for $\beta p_{\text {max }}, \beta_{\epsilon}$ and $\rho$, respectively. This demonstrates that the estimated value of respiration parameter $\rho$ is less reliable than the estimated values of the photosynthesis parameters. On the other hand, comparison of relative sensitivities demonstrates that the simulated CGR is more affected by changes in one of the photosynthesis parameters than by changes in $\rho$ (Table 4 ). On a clear day $\beta p_{\max }$ and $\beta_{\epsilon}$ were found equally important. On a cloudy day the simulated reduction in CGR was more sensitive to changes in $\beta \in$ than to changes in $\beta p_{\max }$, as large fractions of leaf area received low light intensities during a large fraction of the day. The reliability of the estimated parameter value and the relative sensitivity of the parameter in the model both influenced the percentage change of the simulated reduction in CGR given in table 4 . The result clearly indicates that, with respect to the simulation of the reduction in CGR due to leaf blast, the estimation of $\beta_{\epsilon}$ is the weakest link.

Vertical disease distribution. Daamen (1989) described vertical distribution of mildew in wheat by a simple power function:

$\mathrm{CA}_{\text {lcsion }}=\left(\mathrm{CA}_{\text {leaf }}\right)^{\mathrm{h}}$

in which $\mathrm{CA}_{\text {lesion }}$ is the cumulative lesion area divided by the total lesion area, and $\mathrm{CA}_{\text {leaf }}$ is the same quotient for green leaf area. Both variates were calculated from top to bottom of the canopy. Parameter $b$ describes the steepness of the gradient. A value of 1.29 gave a good description of the vcitical distribution of leaf blast observed in plot B. The model was used to determine values of b resulting in a $5 \%$ deviation of the simulated reduction in CGR due to blast lesions. Small changes in the steepness of the disease gradient already caused such a deviation, indicating that simulated CGR is sensitive to vertical disease distribution (Fig. 5B). In a further analysis the canopy was dissected in five layers of equal

Neth. J.PI. Path. 99 (1993) 

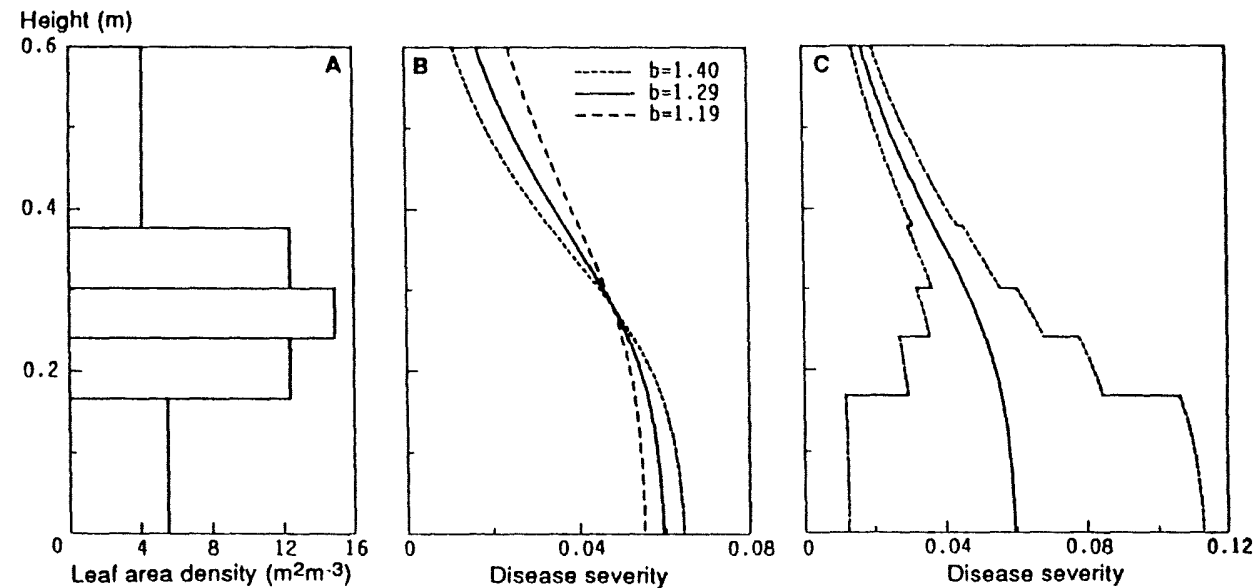

Fig. 5. Vertical distribution of leaf area (A) and disease severity (B, C) as observed in plot B. The rectangles in $A$ represent five layers of equal leaf area. A power function was used to describe actual disease distribution $(b=1.29)$ and distributions leading to a $5 \%$ deviation in the simulated reduction in crop growth rate due to blast lesions (B). The higher sensitivity for disease present in the top of the canopy is illustrated by indicating, layerwise, the change in severity required for a $5 \%$ deviation in the simulated reduction in crop growth rate due to blast lesions (C).

leaf area. For each layer the severity which resulted in a $5 \%$ deviation of the reduction in CGR due to blast lesions was determined (Fig. 5C). The analysis demonstrated that the model is more sensitive to changes in disease severity in the top of the canopy, than to changes in severity in lower canopy layers. Lesions in the top layers of the canopy thus contribute more to the reduction in CGR.

\section{Discussion}

Photosynthesis of rice canopies in the noninoculated plots was accurately simulated with the model. This emphasises the soundness of the well documented photosynthesis and respiration routines, as was previously demonstrated by Kropff and Goudriaan (1989). Likewise the reduction in CER due to leaf blast was properly simulated. This illustrates that the identified damage mechanisms adequately explain the observed reduction in canopy photosynthesis. CGR's of canopies suffering from leaf blast are reduced through a reduction in both radiation use efficiency (RUE) and radiation interception by green leaf area (RI). Although Waggoner and Berger (1987) claimed that yield loss in most pathosystems can be explained through a reduction in RI, several other diseases are reported to affect RUE as well as RI (e.g. Cercospora sp. leafspot in peanuts (Boote et al., 1980) and Verticillium dahliae in potato (Bowden and Rouse, 1991)). The contribution of both components to the overall reduction varies and is related to the relative extent of diseased and dead leaf area.

The three plots in the experiment represent rice crops at various stages of infection, offering the opportunity to theorize about the way the reduction in CGR evolves. After infection with $P$. oryzae lesions develop. The most prominent effect of these lesions is an inhibitory effect on photosynthesis of the surrounding green leaf tissue, which causes a reduced RUE. Simultaneously the lesions decrease the amount of green leaf area, herewith reducing RI. Newly emerging leaves become infected, whereas earlier infected 
leaves are subject to an accelerated senescence. As a result, the fraction diseased leaf area remains more or less constant, whereas the fraction dead leaf area increases. Consequently, the reduction in CGR will increase as a result of an increased reduction in RI (Fig. 6). This analysis suggests that in the long run crop production suffers more from the accelerated senescence of infected leaf tissue than from the initial disturbances in leaf physiology.

The reduction in leaf photosynthetic rate in dependence of leaf blast severity is represented by a curvilinear relation. Non-linearity means that use of averages should be avoided, since their use may lead to serious over- or underestimations (De Wit \& Van Keulen, 1987; Nonhebel, 1992). In the present case this implies that instead of an average disease severity for green leaf tissue, the leaves should be classified according to disease severity. Photosynthesis parameters $\left(P_{\max }, \epsilon\right)$ and the corresponding rate of photosynthesis should be calculated lor each category and their contributions should be added to obtain the rate of crop photosynthesis. A more detailed examination demonstrated that in the present case the error caused by the use of an average severity is relatively small compared to the error caused by uncertainty in $\beta p_{\max }$ and $\beta_{\epsilon}$. This is mainly due to the fact that leaves with a disease severity exceeding 0.30 are hardly found, since these leaves generally die. Moreover, the function that is used to describe the relation between diseases severity and $P_{\text {max }}$ and $\epsilon$ is fairly linear up to a disease severity of 0.30 (Bastiaans, 1991). Saturation would only appear at higher disease severities. This justifies the use of an average disease severity in case of the simulation of the reduction in CGR of rice due to leaf blast.

Vertical disease distribution was recognized as an important determinant of the reduction in CGR. The analysis revealed that lesions in the top layers of the canopy contribute more to the reduction in CGR than lesions on leaves in lower layers. Since the effect of the lesions on $P_{\text {max }}$ and $\epsilon$ differs only slightly, this difference is mainly a reflection of the photosynthesis profile of the canopy, which depends to a great extent on light distribution. The observation implies that recognition of a vertical disease profile becomes particularly important in crops with higher LAl's, since in these situations a considerable difference

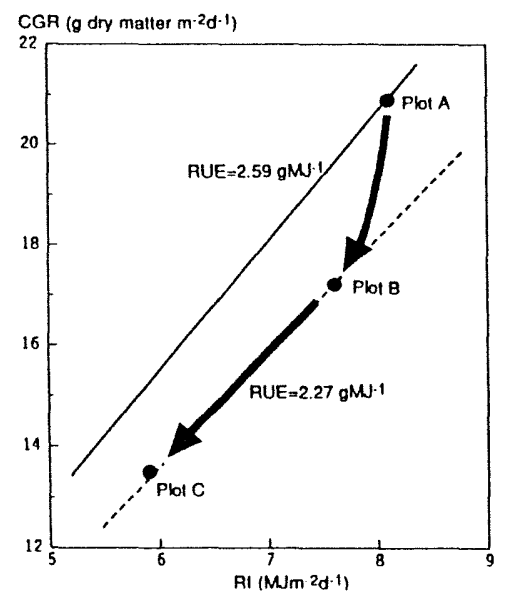

Fig. 6. Simulated crop growth rate (CGR; $g$ dry matter $\left.m^{2} d^{1}\right)$, radiation interception by green leaf area (RI; $\mathrm{MJm}^{-2} \mathrm{~d}^{-1}$ ) and radiation use efficiency (RUE: $\mathrm{g}$ dry matter $\mathrm{MJ}^{-1}$ ) of the rice crop in the 3 experimental plots. The arrows illustrate the hypothesis on the time course of the reduction in CGR due to leaf blast.

Neth.J.Pl.Path. 99 (1993) 
exists between the contribution of upper and lower layers to the overall photosynthetic rate of the canopy. In general, disease monitoring for crop loss assessment should account for vertical disease distribution, or concentrate on the upper layers. In EPIPRE, a disease and pest warning system for wheat, this principle is already applied for powdery mildew and Septoria sp., as disease monitoring is restricted to the upper three leaves (Zadoks, 1989). The presently developed model for effects of leaf blast on canopy photosynthesis of rice may contribute to the determination of an optimal sampling procedure for leaf blast in rice.

\section{Acknowledgements}

Thanks are due to L. Licardo, L. Almario, M. Ilagan, I. Medallon, R. Tagaro, and R.R. Pamplona for their contribution to the experimental work. The staff of the Intermational Rice Research Institute is kindly acknowledged for co-operation and the use of their facilities. Gratitude is extended to Prof. Dr Ir R. Rabbinge and Prof. Dr J.C. Zadoks for comments on earlier versions of the manuscript.

\section{References}

Bastiaans, L., 1991. Ratio between virtual and visual lesion size as a measure to describe reduction in leaf photosynthesis of rice due to leaf blast. Phytopathology 81: 611-615.

Bastiaans, L., 1993. Effects of leaf blast on photosynthesis of rice. 1. Leaf photosynthesis. Netherlands Journal of Plant Pathology 99: 197-20)3

Boote, K.J., Jones, J.W., Mishoe, J.W. \& Berger, R.D., 1983. Coupling pests to crop growth simulators to predict yield reductions. Phytopathology 73: 1.581-1587.

Boote, K.J., Jones, J.W., Smerage, G.H., Barfield, C.S. \& Berger R.D., 1980. Photosynthesis of peanut canopies as affected by leafspot and artificial defoliation. Agronomy Journal 72: 247-252.

Bowden, R.L. \& Rouse, D.I., 1991. Chronology of gals exchange effects and growth effects of Verticillium dahliae infection in potato. Phytopathology 81: 301-310.

Daamen, R.A., 1989. Assessment of the profile of powdery mildew and its damage function at low disease intensities in field experiments with winter wheat. Netherlands Journal of Plant Pathology 95: 85-105.

De Wit, C.T. \& Van Keulen, H., 1987. Modelling production of field crops and its requirements. Geoderma 40: 253-265.

Dingkuhn, M., Schnier, H.F., De Datta, S.K., Wijangco, E. \& Doerflling. K., 1990. Diumal and developmental changes in canopy gas exchange in relation to growth in transplanted and direct seeded flooded rice. Australian Journal of Plant Physiology 17: 119-1.34.

Goto, K., 1965. Estimating losses from rice blast in Japan. In: The Rice Blast Disease. Johns Hopkins University Press, Baltimore, Maryland. p. 195-202.

Goudriaan, J., 1982. Potential production processes. In: Penning de Vries, F.W.T. \& Laar, van H.H. (Eds), Simulation of plant growth and crop production. Simulation monographs, Pudoc, Wageningen. p. 98-113.

Goudriaan, J., 1986. A simple and fast numerical method for the calculation of daily totals of crop photosynthesis. Agricultural and Forest Metcorolngy 38: 25I-255.

Goudriaan, J., 1988. The bare bones of leaf angle distribution in radiation models for canopy photosynthesis and energy exchange. Agricultural and Forest Meteorology 43: 155-169.

Johnson, K.B., 1987. Defoliation, disease and growth: A reply. Phytopathology 77: 1495-1497.

Kropff, M.J., 1989. Quantification of $\mathrm{SO}_{2}$ effects on physiological processes, plant growth and crop production. Ph.D. thesis, Wageningen Agricultural University. $201 \mathrm{pp}$.

Kropff, M.J. \& Goudriaan, J., 1989. Modelling short term effects of sulphur dioxide. 3. Effects of $\mathrm{SO}_{2}$ on photosynthesis of leaf canopies. Netherlands Journal of Plant Pathology 95: 265-280.

Mackill, A.O. \& Bonman, J.M., 1986. New hosts of Pyricularia oryzae. Plant Disease 70: 125-127. McCree, K.J., 1970. An equation for the rate of respiration of white clover plants grown under 
controlled conditions. In: Prediction and measurement of pholosynthetic productivity. Pudoc, Wageningen. p. 221-229.

McCree, K.J., 1974. Equations for the rate of dark respiration of white clover and grain sorghum, as functions of dry weight, photosynthetic rate, and temperature. Crop Science 14:509-514.

Nonhebel, S., 1992. Use of weather data in crop growth simulation models. In: Scaife, A. (Ed.), Proceedings of the Second Congress of the European Society for Agronomy. ESA UK Congress Orfice, Welleshourne, UK. p. 156-16.5.

Parton, J.P. \& Logan, J.A., 1981. A model for diurnal variation in soil and air temperature. Agricultural Metcorology 23: 205-216.

Penning de Vries, F.W.T., 1972. Respiration and growth. In: Rees, A.R., Cockshull, K.E., Hand, D.W. \& Hurd, R.J. (Eds), Crop Processes in Controlled Environments. Academic Press, London. p. $327-347$.

Penning de Vries, F.W.T., 1975. The cost of maintenance processes in plant cells. Annals of Botany 39: 77-92.

Penning de Vries, F.W.T., Jansen, D.M., ten Berge, H.F.M. \& Bakema, A., 1989. Simulation of ecophysiological processes of growth in several annual crops. Pudoc, Wageningen. $271 \mathrm{pp}$.

Penning de Vries, F.W.T., van Keulen, H. \& Alagos, J.C., 1990. Nitrogen redistribution and potential production in rice. In: Sinha, S.K. (Ed.), Proceedings of the International Congress of Plant Physiology. New Dehli, India. p. 513-520.

Rabbinge, R. \& Bastiaans, L., 1989. Combination models, crop growth and pests and diseases. In: Rabbinge, R., Ward. S.A. \& Laar, van H.H. (Eds), Simulation and systems management in crop protection. Pudoc, Wageningen. p. 217-239.

Rabbinge, R. \& Rijsdijk, F.H.,1981. Disease and crop physiology: a modeller's point of view. In: Ayres, P.G., (Ed.), Effects of disease on the physiology of the growing plant. Cambridge University Press, Cambridge. p. 201-220.

Ryle, G.J.A.. Cobby, J.M. \& Powell, C.E., 1976. Synthetic and maintenance respiratory losses of ${ }^{14} \mathrm{CO}_{2}$ in uniculm barley and maize. Annals of Botany 40: 571-586.

Spitters, C.J.T., 1986. Separating the diffuse and direct component of global radiation and its implications for modelling canopy photosynthesis. Part II: Calculation of canopy photosynthesis. Agricultural and Forest Meteorology 38: 231-242.

Spitters, C.J.T., Toussaint, H.A.J.M. \& Goudriaan, J., 1986. Separating the diffuse and direct component of global radiation and its implications for modeling canopy photosynthesis. Part I: Components of incoming radiation. Agricultural and Forest Meteorology 38: 217-229.

Thornley, J.H.M., 1970. Respiration, growth and maintenance in plants. Nature 227: 304-305.

Toyoda, S. \& Suzuki, N., 1957. Histochenical studies on the lesions of rice blast caused by Pyricularia oryzae Cav. III. Changes in the respiration of infected tissues. Annals of the Phytopathological Socicty of Japan 22: 173-177.

Waggoner, P.E. \& Berger, R.D., 1987. Defoliation, disease, and growth. Phytopathology 77: 393-398.

Zadoks, J.C., 1989. EPIPRE, a computer-based decision support system for pest and disease control in wheat: its development and implementation in Europe. In: Leonard, K.J. \& Fry, W.E. (Eds), Plant disease epidemiology. Volume 2: Genetics, resistance, and management. McGraw-Hill Publishing Company, New York. p. 3-29. 